\title{
MENGINTEGRASIKAN PEMBELAJARAN MATEMATIKA BERBASIS BUDAYA BANTEN PADA PENDIRIAN SD LABORATORIUM UPI KAMPUS SERANG
}

\section{Supriadi ${ }^{1}$, Andika Arisetyawan ${ }^{2} \&$ Tiurlina $^{3}$}

1,2,3PGSD UPI Kampus Serang

1,2,3 Jl. Ciracas Serang Banten

'Email: supriadi.upiserang@upi.edu

2Email: andikaaristyawan@upi.edu

3Email: tiurlina@upi.edu

\begin{tabular}{|c|c|}
\hline ABSTRACT & ABSTRAK \\
\hline $\begin{array}{l}\text { This study focused on the characteristics of the } \\
\text { development of teaching materials, teachers } \\
\text { and students in mathematics learning based on } \\
\text { Banten's culture. The Method which is used in this } \\
\text { research are didactical Design Research and } \\
\text { pre-experimental study, the subject of the study is } \\
\text { a second grade of primary school student in the } \\
\text { city of Serang where this research was taking } \\
\text { place in academic year } 2015 / 2016 \text {. The study } \\
\text { stated that: Characteristics of teachers in } \\
\text { mathematics learning based on Banten's } \\
\text { culture,the teachers have the ability of } \\
\text { metapedagogical skill in preparing the learning } \\
\text { process which are divided into three stages: } \\
\text { before, during and after learning. Meanwhile, } \\
\text { before learning the subject, The Students have } \\
\text { to learn more about Banten's culture, Also They } \\
\text { discussed and solved the problems using it. On } \\
\text { the last stage, the students reflected their } \\
\text { knowledge and shared their impressions after } \\
\text { learning. } \\
\text { Keywords: mathematical instruction, Banten } \\
\text { Culture, Didactical Design Research. }\end{array}$ & $\begin{array}{l}\text { Penelitian ini berfokus pada karakteristik } \\
\text { pengembangan bahan ajar, guru dan siswa } \\
\text { dalam pembelajaran matematika berbasis } \\
\text { budaya Banten. Metode yang digunakan } \\
\text { adalah penelitian Didactical Design Research } \\
\text { dan pre-eksperimen dengan subjek penelitian } \\
\text { yang digunakan adalah siswa kelas II SD swasta } \\
\text { di kota Serang tahun ajaran 2015/2016. Hasil } \\
\text { penelitian menyatakan bahwa: Karakteristik guru } \\
\text { dalam pembelajaran matematika berbasis } \\
\text { budaya Banten guru memiliki kemampuan } \\
\text { metapedadidaktis dalam menyiapkan proses } \\
\text { pembelajaran yang dibagi dalam tahap } \\
\text { sebelum, saat dan setelah pembelajaran. Siswa } \\
\text { memiliki karakteristik dimana sebelum } \\
\text { pembelajaran siswa akan belajar mengenai } \\
\text { budaya Banten, saat belajar siswa akan } \\
\text { berdiskusi dan memecahkan masalah dengan } \\
\text { menggunakan budaya Banten, dan setelah } \\
\text { pembelajaran siswa akan melakukan refleksi } \\
\text { terhadap pengetahuan dan kesan setelah } \\
\text { mendapatkan pembelajaran berbasis budaya } \\
\text { Banten. } \\
\text { Kata kunci: pembelajaran matematika, budaya } \\
\text { Banten, Didactical Design Research. }\end{array}$ \\
\hline
\end{tabular}

How to Cite: Supriadi, S., Arisetyawan, A., \& Tiurlina, T. (2016). MENGINTEGRASIKAN PEMBELAJARAN MATEMATIKA BERBASIS BUDAYA BANTEN PADA PENDIRIAN SD LABORATORIUM UPI KAMPUS SERANG. Mimbar Sekolah Dasar, 3(1), 118. doi:http://dx.doi.org/10.17509/mimbar-sd.v3i1.2510.

PENDAHULUAN ISU pendidikan Indonesia di tahun 2010 adalah mulai dilaksanakannya pendidikan berbasis karakter. Pendidikan matematika sangat berperandalam mewujudkan karakter bangsa yang cerdas, ulet, jujur, kritis dan kreatif. Mulai tahun 1986, suatu inovasi pembelajaran matematika digagas oleh D'Ambrosio (1990), seorang ahli pendidikan matematika dari Brasil yang mencoba menghubungkan pembelajaran matematika dengan budaya yang dipahami siswa saat belajar matematika. Ethnomathematics merupakan suatu cara 
Supriadi, Andika Arisetyawan \& Tiurlina, Mengintegrasikan Pembelajaran Matematika...

yang sangat tepat dalam mendidik siswa yang berkarakter berbasis budaya bangsa.

Ethnomathematics relatif baru sebagai bidang penelitian dalam pendidikan matematika. Sebagai pandangan matematika sebagai "budaya bebas" dan "universal" telah lebih cepat muncul dalam kurikulum, sedangkan ethnomathematics muncul relatif terlambat. Prestasi pendidikan matematika Indonesia di dunia Internasional selalu di urutan terendah daripada negara-negara lain. Ini disebabkan kurikulum Indonesia masih eurosentris, sehingga dianggap kurang cocok dengan dengan budaya dan karakter siswa Indonesia. Bangsa-bangsa seperti Jepang, Korea, Cina dan bangsabangsa Tiongkok lainnya telah lama menggunakan budaya mereka dalam pembelajaran matematika. Sehingga mereka dapat maju pesat dalam segala bidang. Keberhasilan negara Jepang dan Tionghoa dalam pembelajaran matematika karena mereka menggunakan Etnomatematika dalam pembelajaran matematikanya (Kurumeh, 2004).

Ruang lingkup ethnomathematics dalam pendidikan matematika yaitu menekanan pada analisis pengaruh dari faktor sosialbudaya dalam kegiatan belajar-mangajar dan pengembangan matematika itu sendiri. Matematika merupakan produk budaya. Setiap kebudayaan dan subkultur mengembangkan matematikanya sendiri.
Matematika dianggap menjadi universal, berisi semua aktivitas manusia. Sebagai produk budaya matematika memiliki sejarah. Dalam kondisi ekonomi, sosial dan budaya tertentu, hal itu muncul dan berkembang dalam arah tertentu, di bawah kondisi lain, ia muncul dan berkembang di arah lain. Dengan kata lain, pengembangan matematika tidak unilinear.

Pembelajaran matematika berbasis budaya (ethnomathematics) bukan berarti menjadikan subjeknya masyarakat yang primitif atau kembali pada jaman dahulu. Namun bagaimana budaya yang sudah menjadi suatu karakter asli bangsa dapat terus bertahan dengan disesuaikan waktu dan jamannya saat ini. Ethnomathematics adalah suatu pendekatan pengajaran dan pembelajaran matematika yang dibangun atas pengetahuan siswa sebelumnya, latar belakang, peran lingkungan bermain dalam hal konten dan metode, dan pengalaman masa lalu dan lingkungannya saat ini (D'Ambrosio, 1990).

Pengamatan yang dilakukan oleh Supriadi (2012) selama 1 semester di UPI Kampus Serang, diperoleh data bahwa hampir seluruhnya (80\%) dari 80 orang mahasiswa tidak memahami budaya yang ada saat pembelajaran matematika berlangsung. Sehingga tampak dari hasil tes matematika berbasis budaya Banten yang rendah dengan rerata $50 \%$. 
Permasalahan di atas disebabkan bahwa pembelajaran matematika di SD, SMP, SMA dan PT kurang menyajikan budaya sebagai tema atau konstek dalam pembelajaran. Pembelajaran berbasis budaya membawa budaya lokal yang selama ini tidak selalu mendapat tempat dalam kurikulum sekolah (Sardjiyo \& Pannen, 2005).

Penelitian ini akan difokuskan pada bagaimana upaya mengintegrasikan pembelajaran matematika pada tahapan pendirian SD Laboratorium UPI Kampus Serang dengan mengoptimalkan Budaya Banten sebagai pondasi pembentukan karakter, terutama berfokus pada karakteristik guru, materi dan siswa dalam pembelajaran matematika yang berbasis budaya Banten.

Tujuan dari penelitian ini adalah untuk mengetahui:

1. Bagaimana karakteristik guru SD Laboratorium UPI Kampus Serang dalam pembelajaran matematika.

2. Bagaimana karakteristik Materi SD Laboratorium UPI Kampus Serang dalam pembelajaran matematika.

3. Bagaimana karakteristik siswa SD Laboratorium UPI Kampus Serang dalam pembelajaran matematika.

\section{Pembelajaran Ethnomathematics Definisi Ethnomathematics}

Pembelajaran ethnomathematics pertama kali digagas oleh D'Ambrosio pada tahun 1985 dan Nunes pada tahun
1992 (Sardjiyo \& Pannen, 2005). Definisi ethnomathematics berasal dari kata ethno yang mengacu pada sosial konteks budaya yang terdiri dari bahasa, jargon, kode perilaku, mitos dan simbol. Mathema berarti menjelaskan, mengetahui, memahami kegiatan seperti penyandian, mengukur, mengelompokkan, menyimpulkan dan pemodelan. Tics berarti teknik, dengan kata lain etno mengacu pada anggota kelompok di dalam lingkungan budaya diidentifikasi oleh tradisi budaya mereka, kode simbol, mitos dan cara khusus yang digunakan untuk berpikir dan untuk menyimpulkan (Rosa \& Orey, 2007). Ethnomathematics merupakan bidang interdispliner yang meliputi antropologi budaya matematika, pendidikan matematika dan kognisi matematika (Matang, 2006). Ethnomathematics merupakan irisan dari tiga himpunan disiplin ilmu: matematika, antropologi budaya dan pemodelan model matematika (Rosa \& Orey, 2006).

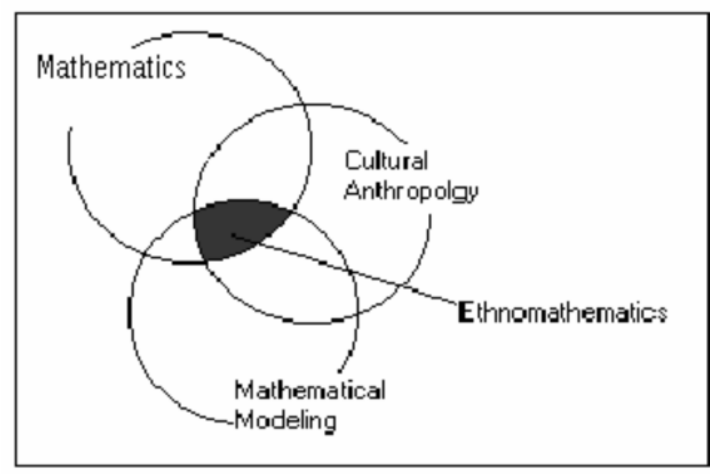

Gambar 1. Definisi Ethnomathematics Adopsi dari Rosa \& Orey, 2006. 
Supriadi, Andika Arisetyawan \& Tiurlina, Mengintegrasikan Pembelajaran Matematika...

\section{Budaya dan Matematika}

Definisi budaya adalah sebuah keseluruhan kompleks yang mencakup pengetahuan, kepercayaan, seni, hukum, moral, adat, dan setiap kemampuan lain dan kebiasaan yang ada oleh manusia sebagai anggota masyarakat (Tyler, 1871).

Budaya menurut Koentjaraningrat (2002) sebagai seluruh total dari pikiran, karya dan hasil karya manusia yang tidak berakal kepada nalurinya dan hanya dicetuskan oleh manusia sesudah proses belajar.

Matematika adalah produk dari budaya yang berbasis kegiatan sosial manusia dan semua masyarakat memiliki praktik-praktik matematika yang dianggap paling sesuai dengan kehidupan sehari-hari dan budayanya. Sistem ini disebut sebagai ethnomathematics (Matang, 2006). Selain itu, matematika diidentifikasi sebagai kegiatan budaya dalam masyarakat tradisional dan non tradisional (Rosa \& Orey, 2007). Matematika dalam ethnomathematics dipandang sebagai suatu disiplin ilmu yang terikat dengan budaya dan nilai-nilai sosial dalam kehidupan mahasiswa, jelas ini sangat bertentangan dengan pendapat selama ini bahwa matematika adalah sebagai disiplin ilmu yang bebas dari budaya dan nilai-nilai sosial.

Matematika, untuk waktu yang lama dianggap sebagai disiplin netral dan bebas budaya dan dihapus dari nilai-nilai sosial (Bishop, et al., 1993; D'Ambrosio, 1990). Tidak ada gunanya matematika diajarkan sebagai objek abstrak dan bebas dari budaya (Bishop, et al., 1993).

Schultes \& Shannon (1997) menemukan bahwa banyak siswa telah mendapatkan penghargaan yang lebih besar untuk matematika setelah mempelajari subjek materi dari perspektif. Budaya ini telah memberikan kontribusi untuk siswa merasa lebih nyaman dan percaya diri tentang membahas konsep-konsep matematika. Menurut Rosa \& Orey (2007), pendekatan matematika disajikan sebagai tanggapan budaya terhadap kebutuhan siswa dengan membuat koneksi antara latar belakang budaya dan matematika. Pendekatan ini mendukung pandangan bahwa matematika dipahami sebagai produk budaya yang telah dikembangkan sebagai hasil dari berbagai kegiatan (Bishop, et al., 1993).

Pernyataan tersebut mengemukakan bahwa matematika dalam pembelajaran ethnomathematics merupakan suatu produk atau hasil karya dari suatu budaya yang dihasilkan oleh manusia dalam kehidupannya, sehingga matematika memiliki nilai-nilai sosial dan terikat dengan budaya setempat. Sehingga pembelajaran matematika melalui ethnomathematics dapat membentuk karakter mahasiswa yang memahami budayanya dengan baik dan mengaplikasikannya dalam kehidupan sehari-hari, sehingga kebudayaan kita 
secara tidak langsung telah dilestarikan keberadaannya melalui pembelajaran matematika selama proses belajar di kelas.

\section{Pembelajaran Ethnomathematics}

Davidson (2000), mengatakan bahwa ethnomathematics adalah seni atau teknik menjelaskan, mengetahui dan memahami konteks budaya beragam. Ethnomathematics menurut Ambrosio (1990), adalah suatu pendekatan pengajaran dan pembelajaran matematika yang dibangun di atas pengetahuan siswa sebelumnya, latar belakang, peran lingkungannya bermain dalam hal konten dan metode, dan pengalaman masa lalunya dan lingkungan sekarang. Kurumeh (2004) pembelajaran ethnomathematics adalah sebuah pendekatan dalam pembelajaran matematika yang digunakan untuk menjelaskan realitas hubungan antara lingkungan budaya dan matematika saat mengajar.

Pembelajaran ethnomathematics sangat dipengaruhi oleh teori konstruktivisme, pengetahuan dikonstruksi secara sosial sehingga belajar merupakan tanggung jawab bersama antara dosen dan mahasiswa di kelas. Perspektif pembelajaran konstruktivis meliputi: 1) pembangunan pengetahuan individu, 2) pengaruh sosial terhadap konstruksi individu, 3) situasional dan persyaratan konstruksi pengetahuan konstektual dan 4) konstruksi sosial dari realitas (Chemark dan
Van der Merwe dalam Matang, 2006). Rosa \& Orey (2007) berpendapat bahwa kurikulum matematika harus didasarkan pada sebuah pendekatan konstruktivis untuk belajar dan berusaha untuk mengubah cara guru matematika membangun lingkungan belajar.

Pembelajaran ethnomathematics memiliki beberapa karakter yaitu: a) penggunaan konsep yang luas dari matematika, khususnya menghitung, menemukan, mengukur, mendesain, bermain dan menjelaskan; b) penekanan dan analisis pengaruh faktor sosial-budaya pada proses belajar, mengajar, dan pengembangan matematika; c) matematika dianggap sebagai produk budaya. Setiap orang, setiap kebudayaan dan setiap subkultur mengembangkan matematika khususnya sendiri (Gerdes, 1994).

Pembelajaran ethnomathematics dapat dibedakan menjadi tiga macam, yaitu belajar tentang budaya, belajar dengan budaya, dan belajar melalui budaya (Goldberg, 2000).

1. Belajar tentang budaya, menempatkan budaya sebagai bidang ilmu.

Proses belajar tentang budaya sudah dipelajari secara langsung oleh mahasiswa melalui mata pelajaran kesenian dan kerajinan tangan, seni, dan sastra, melukis, serta menggambar. Budaya dipelajari dalam satu mata pelajaran khususnya 
Supriadi, Andika Arisetyawan \& Tiurlina, Mengintegrasikan Pembelajaran Matematika...

tentang budaya untuk budaya. Produk budaya yang berlaku dalam sebuah masyarakat dapat digunakan menjadi sebuah metode dalam pemecahan masalah matematika yang akan dilakukan oleh mahasiswa dalam perkuliahan matematika.

2. Belajar dengan budaya.

Belajar dengan budaya bagi mahasiswa meliputi pemanfaatan beragam bentuk perwujudan budaya. Budaya dan perwujudannya menjadi media pembelajaran atau konteks dalam proses belajar di kelas.

3. Belajar melalui budaya

Belajar melalui budaya bagi mahasiswa yaitu dengan memberikan kesempatan dengan menunjukkan pencapaian pemahaman atau makna yang diciptakannya dalam suatu mata pelajaran melalui ragam perwujudan budaya. Belajar melalui budaya merupakan salah satu bentuk multiple representation of learning assessment atau bentuk penilaian pemahaman dalam beragam bentuk. Dengan menganalisis produk budaya yang diwujudkan mahasiswa, dosen dapat menilai sejauh mana produk budaya yang diwujudkan mahasiswa, dosen dapat menilai sejauhmana mahasiswa memperoleh pemahaman dalam sebuah topik matakuliah matematika. Belajar melalui budaya memungkinkan mahasiswa untuk memperhatikan kedalaman pemikirannya, penjiwaannya terhadap konsep atau prinsip yang dipelajari (Sardjiyo \& Pannen, 2005).

\section{METODE \\ Desain Penelitian}

Penelitian ini menggunakan metode campuran Didactical Design Research (DDR) dalam memodifikasi situasi rutin dalam pembelajaran matematika di SD dan penelitian pre-eksperimen.

DDR merupakan sebuah metodologi yang dikembangkan Suryadi (2010), terdiri atas tiga tahapan, yaitu: 1) analisis situasi didaktis (ASD); 2) analisis metapedadidaktis (AM); dan 3) Analisis retrospektif (AR).

Analisis situasi didaktis (ASD) dilakukan oleh seorang dosen atau guru dalam pengembangan bahan ajar sebelum diujicobakan dalam peristiwa pembelajaran. ASD diwujudkan dalam bentuk Disain Didaktis Hipotesis (DDH) termasuk Antisipasi Didaktis dan Pedagogis (ADP) yang akan termuat dalam bahan ajar. ASD berupa sintesis hasil pemikiran dosen tentang berbagai kemungkinan respons siswa yang diprediksi akan muncul pada peristiwa pembelajaran dan langkah-langkah antisipasinya. Analisis metapedadidaktis (AM) dilakukan dosen/guru sebelum, pada saat, dan setelah ujicoba bahan ajar. AM berupa kemampuan dosen/guru untuk dapat memandang peristiwa pembelajaran secara komprehensif, mengidentifikasi dan menganalisis hal-hal penting yang terjadi, 
serta melakukan tindakan cepat dan tepat (scaffolding) untuk mengatasi hambatan pembelajaran (learning obstacles) sehingga tahapan pembelajaran dapat berjalan lancar dan hasil belajar mahasiswa menjadi optimal. AM meliputi tiga komponen yang terintegrasi, yaitu: 1) kesatuan, artinya selama proses pembelajaran berjalan dosen/guru akan senantiasa berpikir tentang keterkaitan antara ADP, HD, dan HP; 2) fleksibilitas, artinya antisipasi yang sudah disiapkan dosen/guru perlu disesuaikan dengan situasi didaktis maupun pedagogis yang terjadi; dan 3) koherensi, artinya setiap situasi didaktispedagogis yang dimunculkan dalam pembelajaran harus mendorong dan memfasilitasi aktivitas belajar siswa yang kondusif dan mengarah pada pencapaian hasil belajar yang optimal. Analisis retrosfektif (AR), dilakukan dosen setelah ujicoba bahan ajar. AR berupa analisis yang mengaitkan hasil analisis situasi didaktis hipotesis dengan proses pengembangan situasi didaktis, analisis situasi belajar yang terjadi sebagai respons atas situasi didaktis yang dikembangkan, serta keputusan yang diambil dosen selama proses analisis metapedadidaktik. Dari AR dilakukan revisi terhadap bahan ajar yang telah dikembangkan sebelumnya sehingga akan dihasilkan suatu bahan ajar yang ideal, yaitu bahan ajar yang sesuai kebutuhan siswa, dapat memprediksi dan mengantisipasi setiap hambatan pembelajaran yang muncul, sehingga tahapan pembelajaran dapat berjalan lancar dan hasil belajar siswa menjadi optimal (Suryadi, 2010).

Tahap selanjutnya adalah tahap pelaksanaan menggunakan metode penelitian pre-eksperimen dengan disain percobaan studi kasus sekali tes (the one shot case study). Penelitian preeksperimen dilakukan untuk melihat hubungan sebab-akibat melalui pemanipulasian variabel bebas dan menguji perubahan yang diakibatkan oleh pemanipulasian tadi, namun subjek penelitian yang dipilih tersebut tidak dikelompokkan secara acak (Ruseffendi, 2005).

Pada penelitian ini, sampel penelitian dipilih tidak secara acak, sampel terdiri dari 1 kelompok yang diberikan perlakuan. Berdasarkan uraian di atas, maka desain penelitian yang digunakan adalah desain studi kasus sekali tes yang secara ringkas digambarkan sebagai berikut:

$x \quad 0$

Keterangan:

0 : Postes

X : Pembelajaran Matematika Berbasis Budaya Banten

\section{Subjek Penelitian}

Penelitian ini dilaksanakan di kelas II SD Islam Khalifah Kota Serang. Tahap pengamatan belajar, Desain Didaktis Awal, dan implementasi dilakukan di SD yang sama. 
Supriadi, Andika Arisetyawan \& Tiurlina, Mengintegrasikan Pembelajaran Matematika...

\section{Instrumen Penelitian}

Instrumen yang digunakan dalam penelitian ini adalah bahan ajar yang dilengkapi dengan pertanyaan untuk siswa, lembar jurnal harian siswa, lembar pengamatan situasi pembelajaran matematika SD, dan daftar isian guru

\section{Teknik Pengumpulan Data}

Beberapa cara yang dilakukan untuk mengumpulkan data pada penelitian ini adalah sebagai berikut:

\section{Tahap DDR:}

a. Wawancara mengenai learning obtacles dilakukan sebelum penyusunan bahan ajar dengan guru kelas.

b. Desain didaktis awal disusun setelah learning obstacles diperoleh untuk divjicoba pada kelas yang dipilih.

c. Revisi desain didaktis disusun setelah mendapatkan learning obstacles dari desain didaktis awal yang telah diujicobakan.

d. Wawancara dilakukan pada siswa dan guru.

\section{Tahap Eksperimen}

a. Tes, dilakukan sesudah (postes) proses pembelajaran

b. Jurnal diberikan kepada seluruh siswa untuk diisi dan dikumpulkan kembali setelah selesai setiap pertemuan.

c. Lembar observasi di isi oleh observer pada setiap pembelajaran matematika berlangsung.

\section{Teknik Analisis Data}

Tahap DDR menggunakan analisis deskripsi kualitatif terhadap situasi pembelajaran yang berlangsung. Sedangkan tahap eksperimen menggunakan uji statistik berupa uji- $\dagger$ satu sampel yang dibandingkan dengan nilai KKM dan rerata kelasnya sehari-hari

\section{HASIL}

\section{Tahap Sebelum Pembelajaran}

Sebelum pembelajaran dimulai, peneliti bekerjasama dengan guru kelas dalam menyusun bahan ajar dan membahas mengenai situasi pembelajaran matematika yang akan diberikan dan yang akan terjadi. Dari diskusi yang dilakukan dengan guru diperoleh informasi bahwa pembelajaran matematika yang menggunakan aspek budaya Banten belum pernah dilakukan, siswa sehari-hari tidak terbiasa menggunakan budaya lokal dalam pembelajaran di kelas dan kehidupan sehari-hari di rumah. Oleh karena itu, sangat diperlukan sebuah bahan ajar yang dapat mengatasi permasalahan tersebut. Bahan ajar yang menggunakan aspek budaya sangat diperlukan dalam pembelajaran, karena sangat sesuai dengan amanat kurikulum pendidikan dasar yang mengedepankan aspek budaya dalam memelihara dan mengembangkan kearifan lokal dalam pembelajaran matematika khususnya, dan pada mata pelajaran lainnya pada umumnya. 


\section{Desain Didaktis}

Berikut instrumen berupa desain didaktis awal yang menggunakan budaya Banten dalam pembelajaran:

\section{Bahasa Ibu}

Coba Ananda menuliskan bilangan dari 110 menggunakan bahasa daerah yang biasa digunakan sehari-hari di rumah!

Desain didaktis tersebut disusun bertujuan menggali kemampuan siswa dalam penggunaan bahasa daerah dalam kehidupan sehari-hari, sehingga penggunakan bahasa daerah di Banten dapat diterapkan di kelas. Prediksi yang didiskusikan bersama guru dan tim peneliti: Siswa akan menjawab:

Untuk siswa yang menggunakan bahasa Sunda dalam kehidupan sehari akan menjawab $1=$ hiji, $2=$ dua, $3=$ tilu, $4=$ opat, $5=$ lima, $6=$ genep, $7=$ tujuh, $8=$ dalapan, 9 = salapan, dan $10=$ sapuluh .

Untuk siswa yang menggunakan bahasa Jawa dalam kehidupan sehari akan menjawab $1=$ siji, $2=$ loro, $3=$ telu, $4=$ papat, $5=\operatorname{limo}, 6=$ anem, $7=$ pitu, $8=$ wolu, $9=$ songo, dan $10=$ dhoso .

Untuk siswa yang terbiasa menggunakan dua bahasa Sunda dan Jawa maka siswa akan memberikan jawaban dengan kedua bahasa. Untuk siswa yang tidak terbiasa Sunda dan Jawa maka kemungkinan siswa akan menjawab dengan menggunakan bahasa Indonesia.
Kemudian guru dan tim peneliti membuat antisipasi pedagogik dalam pembelajaran, kerena terdapat siswa yang tidak terbiasa maka siswa tersebut diajak untuk mendengarkan penyajian dari teman-temannya dalam menyebutkan nama-nama bilangan menggunakan bahasa daerah. Kegiatan pembelajaran dilakukan secara individu agar kompetensi siswa dapat diamati.

Skenario pembelajaran pun guru bersama tim direncanakan sebaik mungkin, sehingga dapat mengurangi learning obstacle dalam pembeajaran di kelas

\section{Tahap Saat Pembelajaran}

Setelah bahan ajar selesai di desain maka tahap selanjutnya adalah pelaksanaan pembelajaran matematika berbasis budaya Banten.

\section{Karakteristik Guru}

Pada saat pembelajaran guru telah menyampaikan tujuan pembelajaran matematika berbasis budaya banten dengan menyampaikan manfaatnya dan memberikan motivasi kepada siswa dengan baik, terutama dalam memelihara budaya di Banten. Konsep dan materi yang disampaikan sudah baik dan benar dalam penyampaiannya. Pemilihan masalah budaya cukup dalam memberikan situasi pembelajaran yang kondusif. Guru dalam memancing siswa dalam mengajukan pertanyaan yang berhubungan dengan budaya sudah baik. Guru pun dapat mendorong siswa 
Supriadi, Andika Arisetyawan \& Tiurlina, Mengintegrasikan Pembelajaran Matematika...

untuk menyelesaikan permasalahan yang diajukan dengan baik. Pengaturan giliran atau kesempatan kepada siswa untuk mengajukan pertanyaan atau pendapat sudah dilakukan dengan baik dalam kelas. Variasi pertanyaan dan teknik bertanya dapat memicu motivasi siswa bertanya. Guru melakukan pengamatan dan mengarahkan pekerjaan siswa dengan baik, sehingga guru dapat membantu dalam proses berpikir siswa. Guru dapat menciptkan diskusi antara siswa dengan siswa dalam kelompok. Pengaturan waktu untuk menyelesaikan permasalahan yang diajukan cukup baik.

\section{Karakteristik Siswa}

Pada saat pembelajaran siswa sudah baik dalam memperhatikan materi pelajaran dan masalah matematika dan budaya yang diajukan guru. Siswa dengan baik mempelajari lembar kerja siswa yang diberikan guru dengan baik. Tanya jawab antara siswa dan guru terhadap materi pelajaran, dan masalah matematikabudaya sudah berjalan dengan baik. Mengemukakan ide untuk menyelesaikan masalah cukup baik dalam pembelajaran. Siswa cukup dapat merumuskan dan mengajukan penyelesaian dari permasalahan yang diberikan guru. Siswa memberikan komentar, tanggapan, pertanyaan, saran, kritikan terhadap penyelesaian yang diajukan siswa lain berjalan dengan baik. Menyakinkan siswa lainnya melalui alasan yang cepat dan tepat terhadap respon yang diajukan berjalan dengan baik. Siswa dapat mengidentifikasi dan mendiskusikan respon yang diajukan. Siswa dapat mempertanyakan gagasan penyelesaian soal atau masalah bila mendapat kritikan dari siswa lain. Siswa sudah cukup baik dalam mengidentifikasi kekurangsempurnaan suatu penyelesaian yang diajukan siswa lain. Siswa dapat membuat simpulan di akhir pembelajaran.

\section{Karakteristik Materi serta Respon Siswa Baik Kinerja maupun Kesannya}

Berikut contoh respon siswa, dari 20 siswa yang memberikan respon.

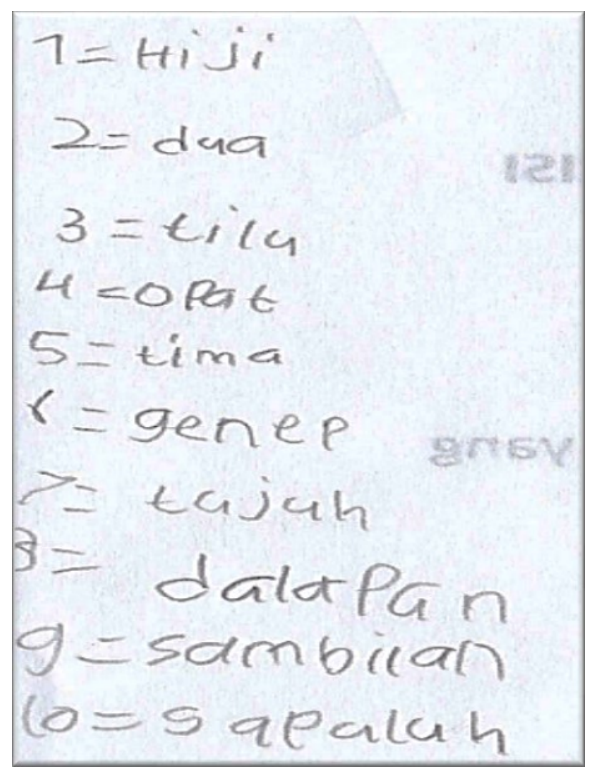

Gambar 2. Respon Siswa 2

Respon siswa 2 sesuai dengan prediksi, siswa menyebutkan nama bilangan menggunakan bahasa Sunda yang sudah dimiliki siswa dalam kehidupan sehari-hari. Namun masih terdapat learning obstacles siswa masih menggunakan bahasa Indonesia dalam penyebutan bilangan sembilan. 


\section{LEMBAR KERUA PESERTA DIDIK SD KHALIFAH KELAS SALMAN ALFARIS} BELAAR MATEMATIKA DENGAN BUDAYA BANTEN

\section{BAHASA IBU (Individu)}

Coba Ananda menuliskan bilangan dari 1-10 menggunakan bahasa daerah yang biasa digunakan sehari-hari di rumah!

$$
\begin{aligned}
& 1 \text { hiji } 2 \text { - dua } 3=\text { tivu } 4=0 \text { pat } 5=\text { time } 6=\text { gre }
\end{aligned}
$$

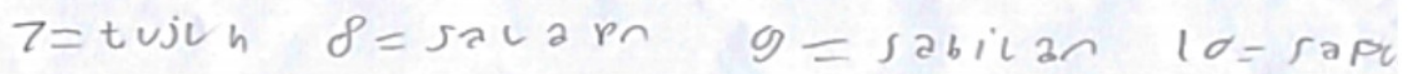

\section{Gambar 3. Respon Siswa 9}

Respon siswa 9 sesuai dengan prediksi, siswa menyebutkan nama bilangan menggunakan bahasa Sunda yang sudah dimiliki siswa dalam kehidupan sehari-hari. Namun masih terdapat learning obstacles siswa masih menggunakan bahasa Indonesia dalam penyebutan bilangan sembilan, selain itu terdapat kesalahan penyebutan nama bilangan pada bilangan delapan dan sembilan. Selain itu, terdapat pula adanya pelafalan dengan menggunakan bahasa Jawa Serang pada bilangan lima.

Respon siswa 10 sesuai dengan prediksi, siswa menyebutkan nama bilangan menggunakan bahasa Sunda yang sudah dimiliki siswa dalam kehidupan sehari-hari.

LEMBAR KERUA PESERTA DIDIK SD KHALIFAH KELAS SALMAN ALFARISI

BELAJAR MATEMATIKA DENGAN BUDAYA BANTEN

BAHASA IBU (Individu)

Coba Ananda menuliskan bilangan dari 1-10 menggunakan bahasa daerah yang biasa digunakan sehari-hari di rumah!

l=hisi $\quad g=$ sala $p$ an

$z=1$ in

$3=t j u$

$4=0$ put

$5=$ lima

$6=9$ eneP

$7=$ tนJuh

$10=\operatorname{sap}$ iuh

odalapan 


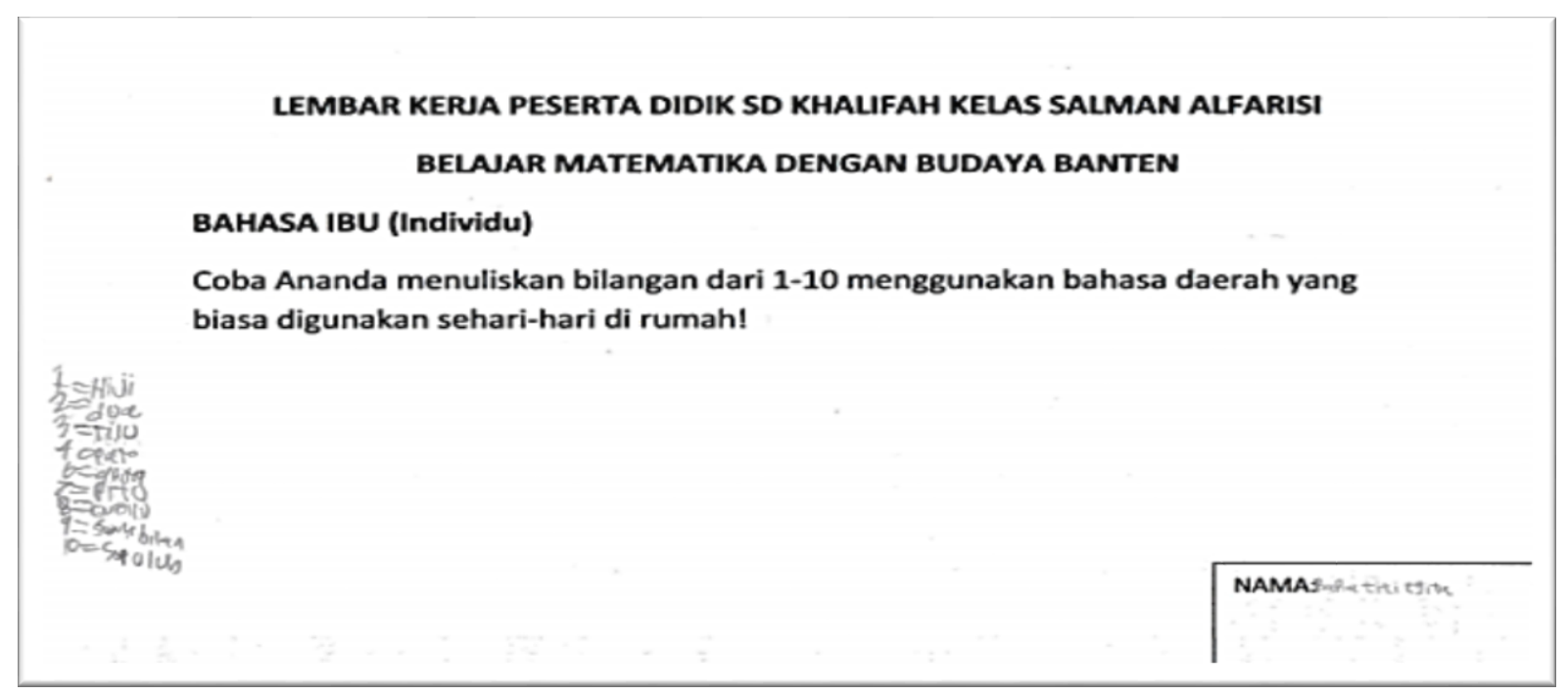

Gambar 5. Respon Siswa 15

Respon siswa 15 sesuai dengan prediksi, siswa menyebutkan nama bilangan menggunakan bahasa Sunda dan Jawa yang sudah dimiliki siswa dalam kehidupan sehari-hari. Namun masih terdapat learning obstacles siswa lupa menuliskan bilangan lima.
Respon siswa 19 sesuai dengan prediksi, siswa menyebutkan nama bilangan menggunakan bahasa Jawa yang sudah dimiliki siswa dalam kehidupan sehari-hari. Namun masih terdapat learning obstacles siswa tidak dapat menyebutkan bilangan dari enam sampai sepuluh.

\section{LEMBAR KERJA PESERTA DIDIK SD KHALIFAH KELAS SALMAN ALFARISI \\ BELANAR MATEMATIKA DENGAN BUDAYA BANTEN}

BAHASA IBU (Individu)

Coba Ananda menuliskan bilangan dari 1-10 menggunakan bahasa daerah yang biasa digunakan sehari-hari di rumah! Si Ji.L or O.TLV. Papst. Lime. 
LEMBAR KERJA PESERTA DIDIK SD KHALIFAH KELAS SALMAN ALFARISI

BELAJAR MATEMATIKA DENGAN BUDAYA BANTEN

\section{BAHASA IBU (Individu)}

\section{Coba Ananda menuliskan bilangan dari 1-10 menggunakan bahasa daerah yang biasa digunakan sehari-hari di rumah! bâHazsapio}

\section{IEHiij}

$2+142$

$3= \pm i g$ s

$4=022 t$

$5=\operatorname{limA}$

$6=$ enem

$7=\operatorname{taj} 4 \mathrm{H}$

NAMA:ANO

$8=129217$

$g=50$ in bi $b 0$

\section{Gambar 7. Respon Siswa 20}

Respon siswa 20 sesuai dengan prediksi, siswa menyebutkan nama bilangan menggunakan bahasa Sunda dan Jawa yang sudah dimiliki siswa dalam kehidupan sehari-hari. Namun masih terdapat learning obstacles siswa belum tepat dalam menyebutkan bilangan delapan.

\section{Tahap Setelah Pembelajaran}

\section{Refleksi dengan Guru}

Guru belum pernah menggunakan pembelajaran matematika berbasis budaya banten, sehingga guru tertarik untuk menggunakannya dalam pembelajaran. Guru sangat setuju bahwa pemberian aspek budaya Banten dalam pembelajaran matematika sangat bisa diterapkan. Menurut pendapat guru bahwa terdapat kelebihan pembelajaran matematika berbasis budaya banten yaitu kita bisa mengenalkan budaya Banten secara tidak langsung dalam pembelajaran matematika. Menambah wawasan siswa terhadap budaya banten, dan membiasakan diri siswa mencintai aneka ragam budaya banten. Saran dari guru terhadap pembelajaran sebaikna diikuti dengan bahasa Banten yang kemudian diselingi dengan artinya, membiasakan siswa dan guru bertanyajawab menggunakan bahasa/budaya Banten. Soal yang disajikan sangat bermanfaat sehingga siswa dapat mengingat budaya dan menggali budayanya.

\section{Refleksi dengan Siswa}

Respon siswa setelah belajar matematika dengan menggunakan pembelajaran matematika berbasis budaya banten, siswa 1 merasa senang belajar dengan 
Supriadi, Andika Arisetyawan \& Tiurlina, Mengintegrasikan Pembelajaran Matematika...

menggunakan bahasa daerah. Siswa 2 mengatakan senang karena gampang belajar matematatika dengan menggunakan bahasa daerah. Walaupun siswa 2 menuliskan responnya menggunakan bahasa sunda, namun siswa 2 pun menyukai bahasa Jawa dalam penggunaan bahasa sehariharinya. Siswa 3 mengatakan senang belajar matematika dengan menggunakan bahasa Sunda dan bahasa Jawa.

Respon siswa setelah belajar matematika dengan menggunakan pembelajaran matematika berbasis budaya Banten, siswa 4 merasa senang belajar dengan menggunakan bahasa daerah. Siswa 5 mengatakan senang belajar matematika dengan menggunakan bahasa sunda. Siswa 6 mengatakan senang belajar matematika dengan menggunakan budaya Banten.

Respon siswa setelah belajar matematika dengan menggunakan pembelajaran matematika berbasis budaya banten, siswa 7, 8 dan 9 merasa senang belajar matematika dengan menggunakan bahasa Sunda.

Respon siswa setelah belajar matematika dengan menggunakan pembelajaran matematika berbasis budaya banten, siswa 10, 11 dan 12 merasa senang belajar matematika dengan menggunakan bahasa Sunda.
Respon siswa setelah belajar matematika dengan menggunakan pembelajaran matematika berbasis budaya banten, siswa 13 merasa senang belajar dengan menggunakan bahasa Sunda dan Jawa. Siswa 14 mengatakan senang belajar matematika dengan menggunakan bahasa daerah, sehingga cepat lancar berbicara dengan bahasa budaya Banten. Siswa 15 mengatakan senang belajar matematika dengan menggunakan budaya Banten.

Respon siswa setelah belajar matematika dengan menggunakan pembelajaran matematika berbasis budaya banten, siswa 16 dan 18 merasa senang belajar matematika dengan menggunakan Budaya Banten. Siswa 17 senang belajar matematika dengan bahasa Sunda dan Jawa.

Respon siswa setelah belajar matematika dengan menggunakan pembelajaran matematika berbasis budaya banten, siswa 19 merasa senang belajar matematika dengan menggunakan Budaya Banten. Siswa 20 senang belajar matematika dengan bahasa daerah.

\section{Analisis Statistik}

Berdasarkan lembar yang dikerjakan siswa, setelah keseluruhan hasil pekerjaan siswa dikumpulkan, kemudian diperiksa, diolah dan dianalisis. Penilaian yang diberikan terhadap hasil kerja siswa tersebut dapat dilihat pada Tabel 1 sebagai berikut. 
Tabel 1. Data Nilai Siswa

\begin{tabular}{|l|l|l|}
\hline \multicolumn{1}{|c|}{ No. } & Siswa & \multicolumn{1}{c|}{ Nilai } \\
\hline 1 & $\mathrm{~S} 1$ & 70 \\
\hline 2 & $\mathrm{~S} 2$ & 90 \\
\hline 3 & $\mathrm{~S} 3$ & 90 \\
\hline 4 & $\mathrm{~S} 4$ & 90 \\
\hline 5 & $\mathrm{~S} 5$ & 90 \\
\hline 6 & $\mathrm{~S} 6$ & 70 \\
\hline 7 & $\mathrm{~S} 7$ & 70 \\
\hline 8 & $\mathrm{~S} 8$ & 80 \\
\hline 9 & $\mathrm{~S} 9$ & 70 \\
\hline 10 & $\mathrm{~S} 10$ & 100 \\
\hline 11 & $\mathrm{~S} 11$ & 70 \\
\hline 12 & $\mathrm{~S} 12$ & 70 \\
\hline 13 & $\mathrm{~S} 13$ & 80 \\
\hline 14 & $\mathrm{~S} 14$ & 80 \\
\hline 15 & $\mathrm{~S} 15$ & 70 \\
\hline 16 & $\mathrm{~S} 16$ & 70 \\
\hline 17 & $\mathrm{~S} 17$ & 80 \\
\hline 18 & $\mathrm{~S} 18$ & 90 \\
\hline 19 & $\mathrm{~S} 19$ & 50 \\
\hline 20 & $\mathrm{~S} 20$ & 70 \\
\hline Rerata & & 77,5 \\
\hline & & \\
\hline
\end{tabular}

Berdasarkan data dari ketuntasan belajar diperoleh $\mathrm{KKM}=65$ dan Rerata kelas sehari-hari $=68.88$, maka akan dilakuka uji perbandingan rerata nilai siswa melalui pembelajaran matematika berbasis budaya banten dengan menggunakan uji-t. Setelah melakukan uji normalitas maka diperoleh data sebagai berikut:

\section{Tabel 2. One-Sample Test terhadap KKM}

\begin{tabular}{|c|c|c|c|c|c|c|}
\hline & \multicolumn{6}{|c|}{ Test Value $=65$} \\
\hline & \multirow[b]{2}{*}{$t$} & \multirow[b]{2}{*}{$d f$} & \multirow{2}{*}{$\begin{array}{l}\text { Sig. (2- } \\
\text { tailed) }\end{array}$} & \multirow{2}{*}{$\begin{array}{l}\text { Mean } \\
\text { Differenc } \\
\mathrm{e}\end{array}$} & \multicolumn{2}{|c|}{$\begin{array}{l}95 \% \text { Confidence } \\
\text { Interval of the } \\
\text { Difference }\end{array}$} \\
\hline & & & & & Lower & Upper \\
\hline Nilai & 4.802 & 19 & .000 & 12.500 & 7.0516 & 17.9484 \\
\hline
\end{tabular}

Dari tabel uji- $\dagger$ di atas diperoleh nilai signifikansi sebesar $0,000<0,05$. Hal ini menyatakan bahwa pembelajaran matematika berbasis budaya memiliki keunggulan dari KKM-nya.

Tabel 3. One-Sample Test terhadap Nilai Keseharian

\begin{tabular}{|c|c|c|c|c|c|c|}
\hline & \multicolumn{6}{|c|}{ Test Value $=68.88$} \\
\hline & \multirow[b]{2}{*}{ t } & \multirow[b]{2}{*}{ df } & \multirow{2}{*}{$\begin{array}{l}\text { Sig. (2- } \\
\text { tailed) }\end{array}$} & \multirow{2}{*}{$\begin{array}{l}\text { Mean } \\
\text { Differenc } \\
\mathrm{e}\end{array}$} & \multicolumn{2}{|c|}{$\begin{array}{l}95 \% \text { Confidence } \\
\text { Interval of the } \\
\text { Difference }\end{array}$} \\
\hline & & & & & Lower & Upper \\
\hline Nilai & 3.311 & 19 & .004 & 8.62000 & 3.1716 & 14.0684 \\
\hline
\end{tabular}

Dari tabel uji- $\dagger$ di atas diperoleh nilai signifikansi sebesar 0,004 $<0,05$. Hal ini menyatakan bahwa pembelajaran matematika berbasis budaya memiliki keunggulan dari rerata kelasnya seharihari.

\section{PEMBAHASAN}

Hasil penelitian ini lebih difokuskan pada aspek guru, siswa dan bahan ajar, yang nantinya dapat dijadikan data pendukung dalam pendirian SD Laboratorium UPI Kampus Serang. Berdasarkan analisis peneliti diperoleh temuan pada karakteristik guru, siswa, dan bahan ajar sebagai berikut.

a. Karakterisitik guru matematika dalam pendirian SD Laboratorium UPI Kampus Serang.

Dalam pembelajaran matematika berbasis budaya Banten, guru harus berperan sebagai fasilitator dan mediator. Oleh karena itu, guru harus terampil dan cakap dalam memahami budaya di Banten terlebih dahulu. Sebagaimana yang dipaparkan oleh Bishop, et al. (1993), bahwa matematika merupakan produk budaya yang telah dikembangkan dari 
Supriadi, Andika Arisetyawan \& Tiurlina, Mengintegrasikan Pembelajaran Matematika...

hasil dari berbagai kegiatan. Tidak mungkin guru akan melakukan pembelajaran matematika berbasis budaya Banten jika dirinya sendiri belum memahami dengan baik budaya Banten.

Selama pelaksanaannya, guru menyuruh siswa merekontruksi pengalamannya sendiri dalam pembelajaran matematika. Guru mengarahkan siswa untuk belajar bekerjasama dalam kelompoknya dalam menemukan sendiri pengetahuannya. Sebelum pembelajaran, guru menyiapkan bahan ajar disertai dengan prediksi dan antisipasi pedagogik didaktik. Guru selalu berdiskusi dan terbuka dalam menerima masukan dan ilmu dari teman sejawat. Guru selalu melakukan refleksi terhadap pembelajaran yang sudah dilakukan.

b. Karakterisitik siswa matematika dalam pendirian SD Laboratorium UPI Kampus Serang.

Berdasarkan analisis peneliti, siswa pada umumnya merasa senang belajar menggunakan pembelajaran matematika berbasis budaya Banten, selain dekat dengan kehidupan siswa, mereka pun dapat belajar bahasa daerah melalui pelajaran matematika. Sebelum pembelajaran siswa dapat mencoba bercakap-cakap dengan menggunakan budaya atau mempelajari budaya banten dengan disuruh oleh guru kelasnya, saat pembelajaran siswa akan berdiskusi dan memecahkan masalah matematika dengan menggunakan budaya, setelah pembelajaran siswa dapat melakukan refleksi terhadap pembelajaran yang sudah diperoleh siswa. Melalui refleksi ini, dapat diketahui apakah pembelajaran etnomatematika sudah benar-benar terjadi atau belum. Dari sini dapat dilihat apakah sudah terjadi pemodelan matematika sebagai bagian dari etnomatematika (Rosa \& Orey, 2006).

c. Karakteristik bahan ajar/materi matematika dalam pendirian SD Laboratorium UPI Kampus Serang Materi akan menggunakan Didactical Design Research. Bahan ajar rancangan guru yang disajikan akan menggunakan pembelajaran matematika berbasis budaya Banten. Sebelum digunakan, bahan ajar diujicoba dan didiskusikan dengan guru dan ahli pembelajaran. Diadakan analisis learning obstacles, situasi didaktis pedagogik, metapedadidaktik, dan analisis retrospektif dalam penyempurnaan bahan ajar, serta untuk memenuhi kriteria bahwa bahan ajar etnomatematika tidak mengganggu jalannya kurikulum yang berlaku (Sardjiyo \& Pannen, 2005).

Selain temuan terhadap aspek kualitatif, peneliti menggunakan pendekatan analisis statistik dengan membandingkan hasil penilaian siswa dengan KKM kelas. Berdasarkan pengolahan data menggunakan uji-† diperoleh data bahwa nilai signifikansi $<5 \%$ yang menyatakan bahwa pembelajaran matematika berbasis budaya Banten memiliki keunggulan yang signifikan. 


\section{SIMPULAN}

Adapun dari kegiatan penelitian ini, diperoleh beberapa temuan penting sebagai berikut:

Pembelajaran matematika berbasis budaya banten dapat memberikan pengaruh yang positif terhadap aspek guru, siswa dan bahan ajar.

a. Karakteristik guru dalam pembelajaran matematika berbasis budaya Banten memiliki kompetensi berpikir yang dituangkan dalam penyajian bahan ajar yang ideal. Guru memiliki kemampuan metapedadidaktis dalam menyiapkan proses pembelajaran yang dibagi dalam tahap sebelum, saat dan setelah pembelajaran.

b. Siswa memiliki karakteristik yang selalu melakukan situasi berpikir terhadap permasalahan budaya Banten yang diberikan guru, sebelum pembelajaran siswa akan belajar mengenai budaya banten, saat belajar siswa akan berdiskusi dan memecahkan masalah dengan menggunakan budaya Banten, dan setelah pembelajaran siswa akan melakukan refleksi terhadap pengetahuan dan kesan setelah mendapatkan pembelajaran berbasis budaya Banten.

C. Materi dalam pembelajaran berbasis budaya Banten melalui kajian Didactical Design Research. Sebelum digunakan, bahan ajar diujicoba dan didiskusikan dengan guru dan ahli pembelajaran. Diadakan analisis learning obstacles, situasi didaktis pedagogik, metapedadidaktik, dan analisis retrospektif.

\section{REFERENS|}

Bishop, A. J., et al. (1993). Significant influences on children's learning of mathematics. Paris, France: UNESCO.

D'Ambrosio, U. (1990). Etnomatemática [ethnomathematics]. São Paulo, Brazil: Editora Ática.

Davidson. (2000). An etnomathematics approach to teaching language minority student. Center for Excellence in Education, North American University.

Gerdes, P. (1994). Reflections on ethnomathematics. For the Learning of Mathematics. 14(2), pp. 19-22.

Goldberg, M. (2000). Art and learning: An integrated approach to teaching and learning in multicultural and multilingual settings. 2nd Ed. New York: Addison Wesley Longman.

Koentjaraningrat. (2002). Kebudayaan Flores. Dalam Koentjaraningrat (Ed.), Manusia dan Kebudayaan di Indonesia. Jakarta: Djambatan Knowing: Proceedings.

Kurumeh. (2004). Effects of ethnomathematics teaching approach on students achievement and interest in geometry and mensuration. Unpublished Ph.D Thesis. University of Nigeria, Nsukka.

Matang, R. A. (2006). Linking ethnomathematics, situated cognition, social constructivisme and mathematics education: An example from Papua New Guinea. ICME-3 Conference Paper, New Zealand.

Ruseffendi, E. T. (2005). Dasar-dasar penelitian pendidikan dan bidang noneksakta lainnya. Bandung: Tarsito.

Rosa, M., \& Orey, D. C. (2006). Abordagens atuais do parogram aetnomatemática: delinenandose um caminho para a ação pedagógica [current 
Supriadi, Andika Arisetyawan \& Tiurlina, Mengintegrasikan Pembelajaran Matematika...

approaches in the ethnomathematics as a program: delineating a path toward pedagogical action]. Bolema, $19(26)$, pp. 19-48.

Rosa, M., \& Orey, D. C. (2007). Cultural assertions and challenges towards pedagogical action of an ethnomathematics program. For the Learning of Mathematics, 27(1), pp. 1016.

Sardjiyo \& Pannen. (2005). Pembelajaran berbasis budaya: model inovasi pembelajaran dan implementasi KBK. Jurnal Pendidikan.

Schultes \& Shannon. (1997). Mathematics and culture: a unique liberal arts experience. PRIMUS: Problems, Resources, and Issues in Mathematics Undergraduate Studies. 7(3), pp. 222234.

Supriadi (2012). Memajukan pendidikan Banten berkarakter melalui pembelajaran matematika berbasis budaya Banten. Makalah: Tidak dipublikasikan.

Suryadi, D. (2010). Didactical design research (DDR) dalam Pengembangan Pembelajaran Matematika I. Bandung: Seminar Nasional Pembelajaran MIPA di UM Malang, 13 Novermber 2010.

Tyler, E. B. (1871). Primitive culture. London: Murray. 